\title{
The influence of depth of tensile concrete deterioration on the load bearing strength and deflections of corrosion-damaged floor slabs
}

\author{
Ashot Tamrazyan and Arman Minasyan \\ Moscow State University of Civil Engineering, Yaroslavskoe shosse, 26, Moscow, 129337, Russia
}

\begin{abstract}
The paper considers the change of load-bearing strength and deflections of corrosion-damaged precast reinforced concrete floor slabs in the conditions of cyclic freezing-thawing in full-scale climatic conditions. The aim of the study is to determine the influence of the depth of tensile concrete deterioration on the change in load-bearing strength and deflections. Corrosion-damaged precast reinforced concrete floor slabs were selected and experimental investigation was performed. Based on the results of the study, the influence of the depth of deterioration of tensile zone of concrete on the load-bearing strength and deflections of structures was determined. At the same time, as the loads increase, deflections increase and the height of the compressive zone decreases. In the experimental investigation, changes of the load-bearing strength and deflections of precast reinforced concrete slabs were determined, depending on the depth of tensile concrete deterioration. The performed studies allow us to estimate the load-bearing strength and deflection values of corrosion-damaged reinforced concrete slabs depending on the relative value of the concrete deterioration in the tensile zone without performing additional experiments and calculations.
\end{abstract}

\section{Introduction}

In this work, the influence of the depth of tensile concrete deterioration on the load-bearing strength and deflections of precast reinforced concrete slabs were determined experimentally. The momenta determination and measurement of deflections was carried out by loading the structure stepwise.

Analysis of the results of the study indicated the following: as the plates are damaged, with the increase in the height of tensile concrete deterioration, the stress diagram gets gradually filled in the compressive sectional area and its height decreases, which can lead to the destruction of the structure. At the same time, the shear and bending moment diagram of sectional deformation gets curved. As the slab deflections increase, its load-bearing strength decreases.

Based on the results of the tests, load-bearing strength and deflections depending on the relative hight of tensile concrete deterioration were plotted. In the office processing of experimental data, the relative values of momenta and slabs deflections were approximated depending on the relative height of the deteriorated concrete in the tensile zone. 


\section{Literature review}

A review of the results of existing studies on corrosion-damaged structures shows that a significant part of the experimental investigations were performed in laboratories or on models with varying application severity degrees [1,2]. Decrease in load-bearing strength of deflected reinforced concrete elements with corrosion damage of transverse reinforcement bars is considered in [3].

Experimental studies of corrosion-damaged reinforced concrete slabs taking into account the impact of the depth of concrete deterioration in tensile zone in full-scale climatic conditions were almost never carried out. Some methods of calculation and experimental studies of corrosion-damaged reinforced concrete structures are offered in $[4,5,6,7]$. Experimental studies of the stress-strain state of deflected reinforced concrete elements with cracks are considered in detail in [8].

The influence of full-scale conditions on the concrete characteristics depends on many factors. A general approach to the characteristic of the change of the load-bearing strength in case of corrosion damage of reinforced concrete slabs in the conditions of cyclic freezing-thawing is to assess all the main possible effects of full-scale conditions on the change of the load-bearing strength.

\section{Materials and methods}

Corrosion-damaged reinforced concrete slabs exposed to cyclic freezing-thawing in fullscale climatic conditions of Moscow were chosen. There was deterioration in these slabs in the tensile zone. The scheme of slab deterioration in the bottom zone and character of depth are shown in Fig. 1 and indicated in Table 1.

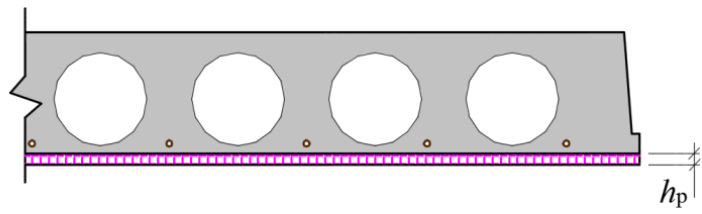

Fig. 1. Scheme of slabs deterioration.

Table 1. Depth of slab deterioration in the bottom zone.

\begin{tabular}{|c|c|}
\hline $\begin{array}{c}\boldsymbol{h}_{\mathbf{p}}-\text { depth of concrete } \\
\text { deterioration in tensile zone } \\
(\mathbf{m m})\end{array}$ & Deterioration scheme \\
\hline$\leq 15$ & 1 \\
\hline$\leq 25$ & 2 \\
\hline$\leq 40$ & 3 \\
\hline
\end{tabular}

According to the set goal, static tests of 28 damaged slabs mounted on a multi-storey building were carried out, and 3 slabs were tested until complete destruction. The slabs dimensions are 6360x1790x220 mm.

Tests have been carried out in accordance with the methods of $[9,10]$ and consisted of 2 stages:

1) stage - loading

The structures were loaded evenly, from the supporting sections to the center by the load of $0.75 ; 10.0 ; 12.5 ; 15.0$ and $17.5 \mathrm{kN} / \mathrm{m}^{2}$. 
Load step is $0.25 \mathrm{kN} / \mathrm{m}^{2}$. Deflections of structures were measured after each loading stage (exposure time 30 minutes).

At the control loading, the deflections of elements were measured repeatedly after 30 minutes (until deflections stopped increasing) [11, 12].

2) stage - measurement

Structure deflections were measured after each loading stage with the help of a dial indicator (with an accuracy of $0.01 \mathrm{~mm}$ ).

A fragment of the scheme of static testing of reinforced concrete hollow-core slab is shown in Fig. 2.

a)

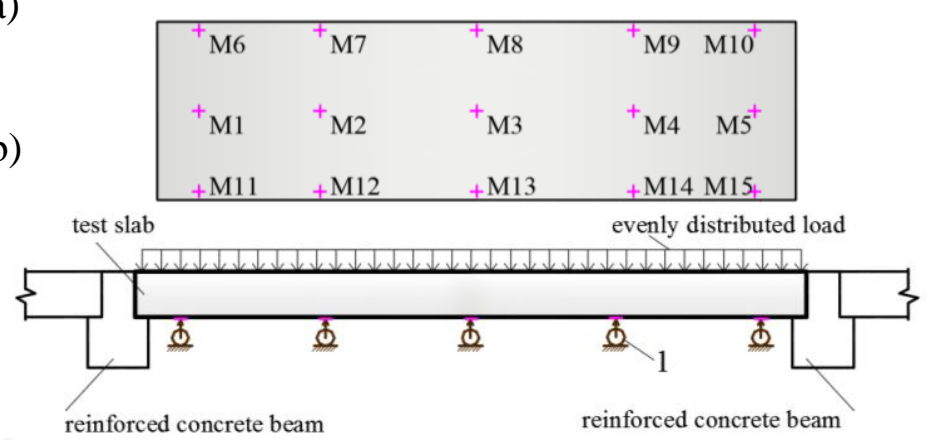

Fig. 2. Scheme of location of marks (a), measurement units to measure slabs deflections (b). 1- Dial indicator (with an accuracy of $0.01 \mathrm{~mm}$ )

\section{Study results}

In the study, the momenta and deflections values were obtained for the 1,2 and 3 slab deterioration scheme depending on the depth of concrete deterioration in tensile zone. Results of the experimental investigations are given in Fig. 3.

Maximum load-bearing strength by the momentum of the base slab is $M_{\text {base }}=M_{0}=135.0 \mathrm{kN} \cdot \mathrm{m}$.

Influence of the concrete deterioration in tensile zone on loadbearing strength is characterized by the coefficient $K_{\mathrm{M} i}$, which is a ratio of load-bearing strength of slabs with

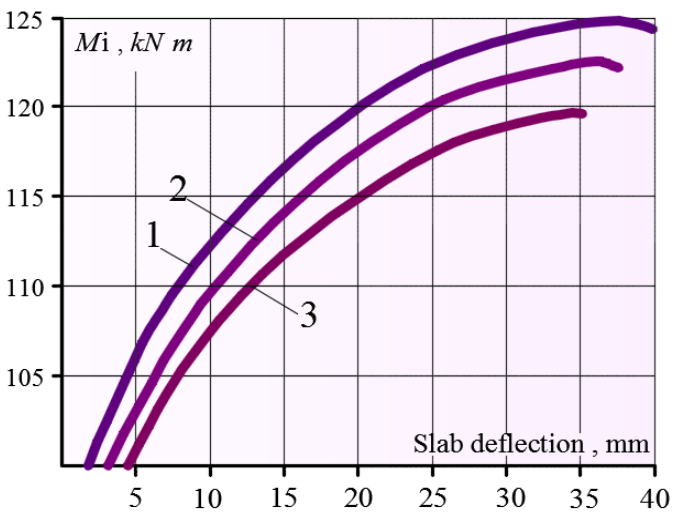

Fig. 3. Diagrams " $M_{i}-f_{i}$ ", by 1,2 and 3 deterioration schemes

In the same way, we set $K_{f i}$ - deflection of deteriorated slab in relation to deflection of the base slab.

Considering slabs deterioration scheme, relative values for momenta in the corresponding sections will be: 


$$
K_{\mathrm{M} 1}=\frac{M_{1}}{M_{0}} ; K_{\mathrm{M} 2}=\frac{M_{2}}{M_{0}} ; K_{\mathrm{M} 3}=\frac{M_{3}}{M_{0}},
$$

where $M_{0}$ - base slab momentum; $M_{1} ; M_{2} ; M_{3}$ - momenta of corrosion-damaged slabs according to the $1^{\text {st }}, 2^{\text {nd }}$ and $3^{\text {rd }}$ schemes.

In the same way, for deflection of corrosion-damaged slabs in relation to the deflection of the base plate will be:

$$
K_{f 1}=\frac{f_{1}}{f_{0}} ; K_{f 2}=\frac{f_{2}}{f_{0}} ; K_{f 3}=\frac{f_{3}}{f_{0}},
$$

where $f_{0}$ - base slab deflection; $f_{1} ; f_{2} ; f_{3}$-deflections of corrosion-damaged slabs according to the $1^{\text {st }}, 2^{\text {nd }}$ and $3^{\text {rd }}$ deterioration schemes.

The test results were analysed and dependences of $K_{\mathrm{M} i}$ and $K_{f i}$ coefficient values on the relative depth of concrete deterioration $\lambda$ were plotted. The $\lambda$ value was calculated using the following formula:

$$
\lambda=\left(h_{p}-a\right) / a,
$$

where $h_{p}$ - depth of concrete deterioration in tensile zone, $\mathrm{mm} ; a-$ distance from tensile face to the gravity center of the section of principal reinforcing bars, $\mathrm{mm}$.

Based on the results of the tests, diagrams $K_{\mathrm{M} i}$ and $K_{f i}$ were plotted in different sections of slabs when loading the structure stepwise.

Dependency of coefficient of load-bearing strength decrease $K_{\mathrm{M} i}$ on the relative deterioration depth of tensile zone according to the results of full-scale tests of 28 slabs is approximated by the following function:

$$
K_{\mathrm{Mi}}=1-\alpha_{M i} \cdot e^{-0,083 / \lambda^{2,35}},
$$

where $\alpha_{m i}=0.35 ; 0.375$ and 0.4 respectively, according to the $1^{\text {st }}, 2^{\text {nd }}$ and $3^{\text {rd }}$ deterioration scheme;

value is $0.083 ; 2.35$ - empirical coefficients; $e$ - base of the natural logarithm. Accordingly, the moment of deflection, taking into account concrete deterioration in tensile zone, can be determined as follows

$$
M_{i}=K_{M i} \cdot M_{0} .
$$

The influence of concrete deterioration on the element deflection was estimated by the coefficient $K_{f i}$, which is a ratio of damaged element deflection $f_{i}$ to the base slab deflection $f_{0}$.

Dependency of the coefficient $K_{f i}$ on the value $\lambda$ is approximated by the function obtained based on the tests of 28 slabs:

$$
K_{f i}=1-\alpha_{f i} \cdot e^{-0,023 / \lambda^{2,35}},
$$

where $\alpha_{f i}=0.9 ; 0.95$ and 1.0 respectively, according to the $1^{\text {st }}, 2^{\text {nd }}$ and $3^{\text {rd }}$ deterioration scheme; value is $0.023 ; 2.35$ - empirical coefficients.

The deflection value of reinforced concrete slabs taking into account concrete deterioration in tensile zone can be determined as follows:

$$
f_{i}=K_{f i} \cdot f_{0} .
$$


The performed experimental studies allow us to conclude that it is necessary to take into account the concrete deterioration in tensile zone when assessing genuine works of corrosion-damaged reinforced concrete slabs.

Fig. 4 shows the diagrams " $K_{f i}-\lambda$ " and " $K_{\mathrm{M} i}-\lambda$ " which allow us to practically determine the load-bearing strength and deflections of corrosion-damaged slabs depending on the relative depth of concrete deterioration.

a)

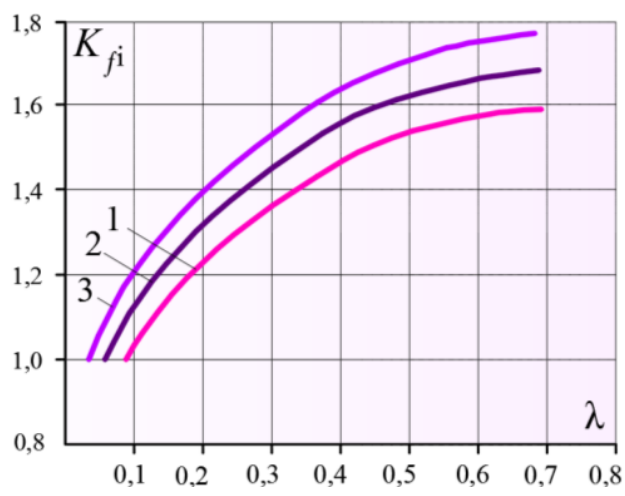

b)

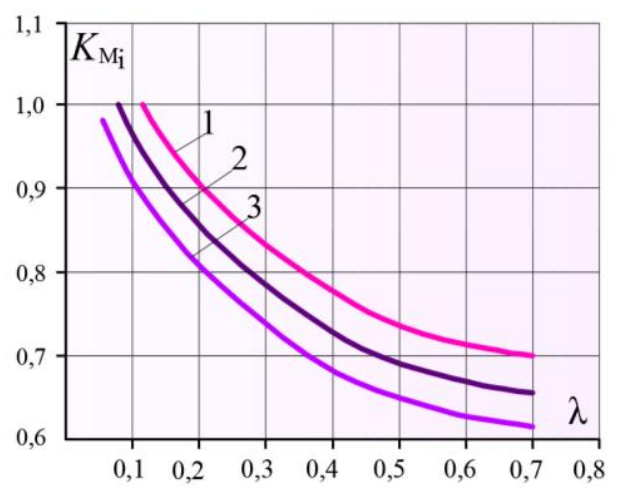

Fig. 4. Dependence diagrams " $K_{f i}-\lambda$ ” (a) and “ $K_{\mathrm{M} i}-\lambda$ ” (b). 1;2 and 3 - respectively, according to $1 \div 3$ deterioration schemes.

Structural analysis of floor slabs, based on the analysis of corrosion damage only to the principal reinforcing bars, without taking into account the concrete deterioration in tensile zone, can give overestimated results in load-bearing strength and underestimated ones in deformability (deflections). Concrete creep in time can be considered according to [13].

\section{Conclusions}

The performed experimental studies indicate the following: For floor slabs, the distribution of momenta and load deflections depends on the depth of concrete deterioration in tensile zone.

As the relative depth of concrete deterioration increases from 0.0 to 0.15 , the loadbearing strength practically does not change. The value $K_{M i}$ is close to 1.0. As deterioration depth increases above $\lambda=0.15$ up to the value of $\lambda=0.40$, a sharp decrease in relative load-bearing strength is noted. The value of coefficient $K_{M i}$ decreases from 1.0 to 0.70 . Further concrete deterioration in tensile zone is accompanied by attenuation of the decrease process of slab load-bearing strength also at the value of $\lambda=0.7$ coefficient $K_{M i}=0.65$.

Analysis of dependences of the coefficient $K_{f i}$ on the relative depth of concrete deterioration $\lambda$ indicates that for slabs, the influence of concrete deterioration in tensile zone appears in the range of the values $\lambda$ from 0.1 to 0.45 . In case of the value $\lambda=0.47$, the values of coefficients $K_{f i}$ are on average equal to 1.6. 
The performed studies allow us to estimate the load-bearing strength and to determine the amount of deflections of corrosion-damaged slabs depending on the depth of tensile concrete deterioration without carrying out additional tests.

\section{Reference}

1. $V u$ K. A. T. Structural Reliability of Concrete Bridges Including Improved ChlorideInduced Corrosion Models/ K.A.T Vu. M.G.Stewart// Structural Safety. V. 22. No/ 4. 2000. - pp/ 313-333

2. Soh, A.K., and Yank, C.H. Numerical Modeling of Interactions Between a Macro-Crack and a Cluster of Micro-Defects //Engineerinf Fracture Mechanics. 2004. Vol. 71, pp. 193-217.

3. Tamrazyan A., Popov D. Reduce of bearing strength of the bent reinforce-concrete elements on a sloping section with the corrosive damage of transversal armature. In the collection: MATEC Web of Conferences 26. Cep. "RSP 2017 - 26th R-S-P Seminar 2017 Theoretical Foundation of Civil Engineering" 2017. C. 00162.

4. Popesco A. I., Antsygin O. I. Phenomenological model of structural analysis under corrosive influences // Construction mechanics and structural analysis. 2006. Issue No. 4

5. Smolyago, G., Drokin S. V., Dronov A. V., Belousov A. P., Pushkin, S. A., Smolyago E. $G$. Estimation of the remaining life of load-bearing strength of precast reinforced concrete floor slabs without beams // News of the South-West State University. 2016. No. 6(69). p. 66-73.

6. Drokin $S$. $V$. Influence of defects on the strength and deformability of intermediate floor elements in framework structures // Ph.D. thesis in Engineering Science 05.23.01. 2012. Belgorod. $201 \mathrm{p}$.

7. Andrade C., Izquierdo. D., Rodriguez J., Advances in design and residual life calculation with regard to rebar corrosion of reinforced concrete // Concrete and reinforced concrete. Conference materials. M. 2005. P. 36-39.

8. Tamrazyan A. G., Orlova M. A. Experimental studies of the stress-strain state of deflected reinforced concrete elements with cracks. In the collection: Modern problems of structural analysis of reinforced concrete structures, buildings and constructions for emergency impacts edited by A.G. Tamrazyan, D.G. Kopanitsa. 2016. p. 507-514.

9. GOST 8829-94 "Reinforced concrete and prefabricated concrete building products. Loading test methods. Assesment of strength, rigidity and crack resistance"

10. SP 63.13330.2012 Concrete and reinforced concrete structures. General terms. Revised edition of SNiP 52-01-2003. 2012. $155 \mathrm{p}$.

11. O.I. Ponomarev, A.A. Minasyan, Accounting of damages of reinforced concrete structures in reconstructed buildings // Vestnik 2, part 1,. Moscow, V.A. Kucherenko CSRIBS, 2010. p. 106-113.

12. Minasyan A.A., Shuklina M.L., Boyajyan A.Sh., Strength, deformability and stability of damaged slabs under static and dynamic loads // Theory and practice of structural analysis of buildings, structures and elements. Analytical and numerical methods. III International research to practice conference. Collected works. MSUCE, 2010, p. 231240.

13. Tamrazyan A. G. To calculation of reinforced concrete elements taking into account the creep and aging based on rheological model of concrete Industrial and civil construction. 2012. No. 7. p. 26-27. 